Оригинальная статья/Original article

УДК 360

DOI: http://doi.org/10.20914/2310-1202-2017-4-289-296

Проектное управление в сфере инноваций: междисциплинарный подход

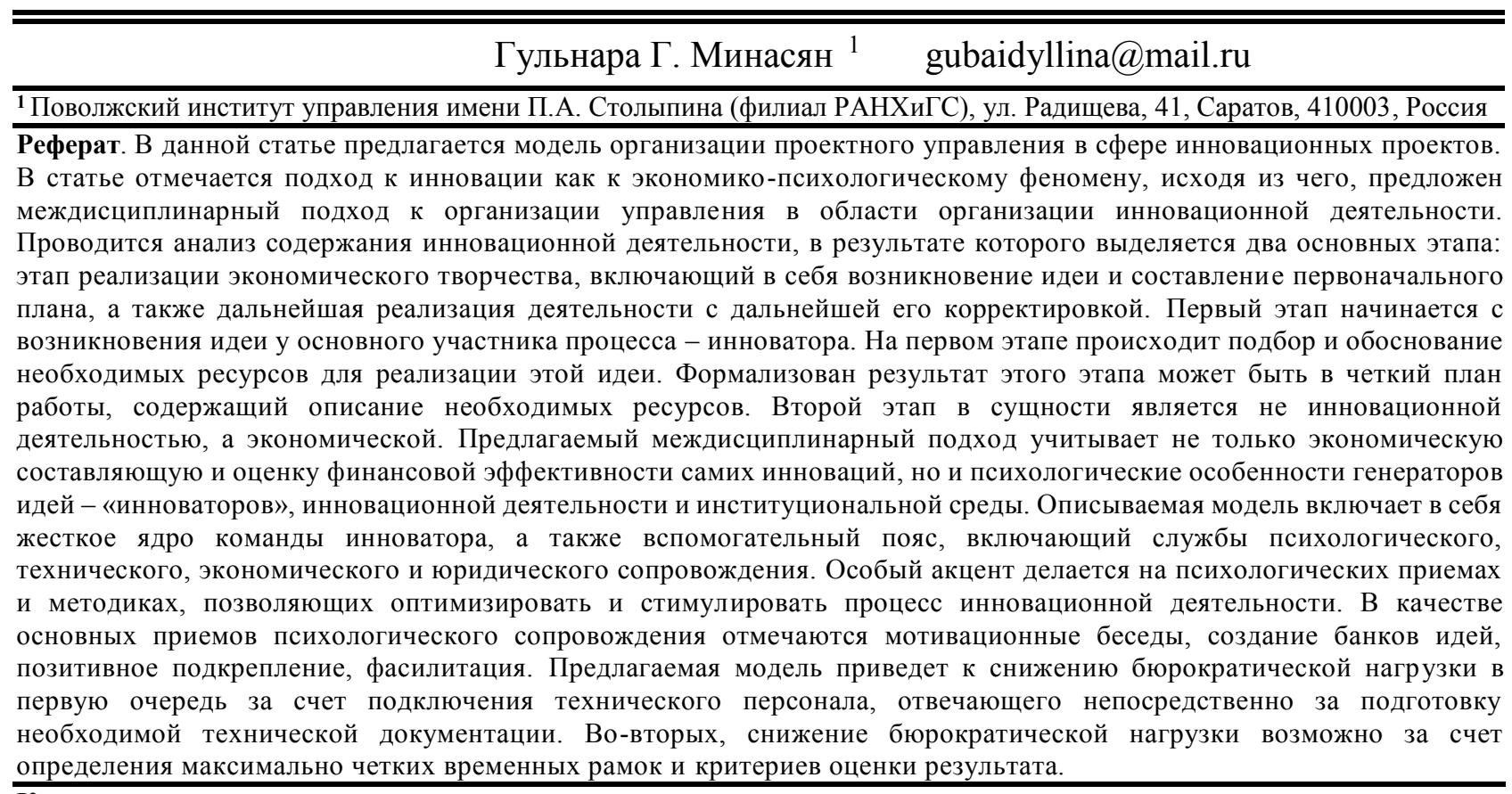
Ключевые слова: проектное управление, инновационная деятельность, экономическая психология, психология инноватора

\title{
Project management in the sphere of innovations: interdisciplinary approach
}

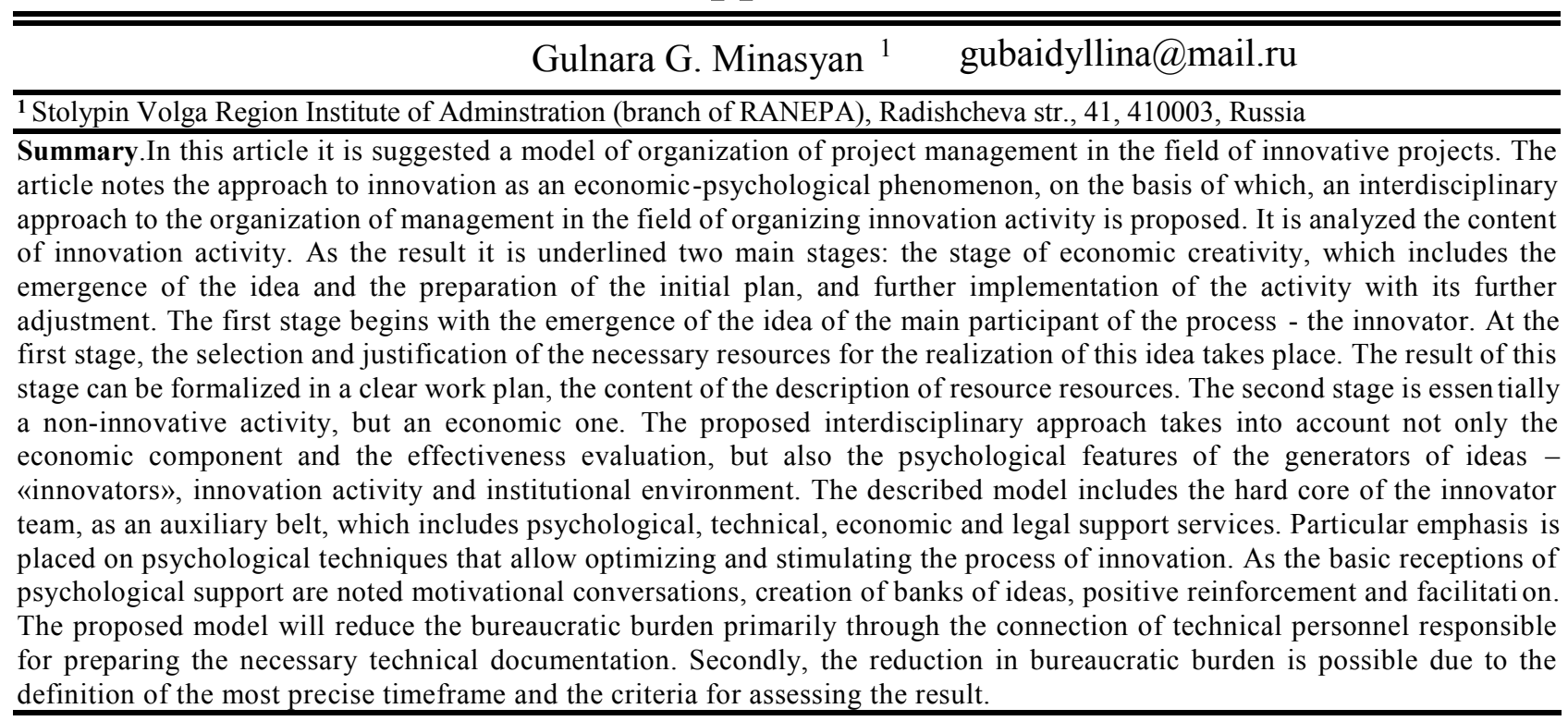
Keywords:project management, innovative activity, economic psychology, psychology of the innovator

Для цитирования

Минасян Г.Г. Проектное управление в сфере инноваций: междисциплинарный подход // Вестник ВГУИТ. 2017. Т. 79. № 4 C. 289-296. doi:10.20914/2310-1202-2017-4-289-296
For citation

Minasyan G.G. Project management in the sphere of innovations: interdisciplinary approach. Vestnik VGUIT [Proceedings of VSUET]. 2017. vol. 79. no. 4. pp. 289-296. (in Russian). doi:10.20914/23101202-2017-4-289-296 


\section{Введение}

Как отмечается в работах Й. Шумпетера, Н.Д. Кондратьева, С.Ю. Глазьева и других ученых, описывающих динамику развития экономических систем, инновации выступают основанием для социально-экономического развития общества. Достаточно подробно описан жизненный цикл инновации после ее появления (Н.Г. Яковенко, М.И. Басс, Н.В. Махров), процесс диффузии инноваций (Г. Тард, Э. Роджерс) и построены математические модели данного процесса (Ф. Басс). Несмотря на множество работ в сфере экономики, социологии, культурологии, описывающих характер жизнедеятельности инновации, до недавнего времени не уделялось должного вниманию процессу инновационной деятельности и человеку, создающему инновации - инноватору.

Жизненный цикл инновации, включающий в себя стадии идеи, реализации, диффузии и рутинизации какого-то нового продукта сам определил проектный характер инновационной деятельности. Во-первых, благодаря конечности процесса внедрения и распространения инновации, во-вторых, благодаря необходимости четкого пошагового планирования деятельности. Описаны жизненные циклы инновационного проекта, включающие в себя стадии НИОКР, непосредственной реализации и завершения, однако, как видно из таблицы 1, выделяемые этапы весьма абстракты и могут быть отнесены к любому проекту, не обязательно инновационному.
Несмотря на актуальность и разработанность темы определение того, что такое инновация остается до сих пор одним из спорных вопросов. Часто в экономической науке инновация определяется как результат инновационной деятельности, которая, в свою очередь, определяется как деятельность по созданию инноваций. Данные определения противоречат одному из основных правил составления определения, согласно которому определяемое понятие не должно повторяться в определяющем ни прямо, ни косвенно. В противном случае возможно возникновение так называемого «порочного круга» в определении, что мы и наблюдаем в случае с инновацией и инновационной деятельностью.

Впервые термин «innovation» появился в научных исследованиях зарубежных культурологов и означал «введение некоторых элементов одной культуры в другую» [Байбаева, Маркаева, Исмаилова, 2016]. Инновация, нововведение (англ. innovation) - это внедрённое новшество, обеспечивающее качественный рост эффективности процессов или продукции, востребованное рынком, которое является конечным результатом интеллектуальной деятельности человека, его фантазии, творческого процесса, открытий, изобретений и рационализации. Примером инновации является выведение на рынок продукции (товаров и услуг) с новыми потребительскими свойствами или качественным повышением эффективности производственных систем. В различных словарях даны определения того, что же такое инновация (таблица 2).

Таблица 1 .

Этапы жизненного цикла инновационного проекта

Table 1.

Stages of the life cycle of the innovation project

\begin{tabular}{|c|c|}
\hline Автор Author & $\begin{array}{l}\text { Стади ижизненного цикла инновационного проекта } \\
\text { Stages of the life cycle of the innovation project }\end{array}$ \\
\hline $\begin{array}{l}\text { Х. Кук и К. Тейт } \\
\text { H. Cooke and К. Tate }\end{array}$ & $\begin{array}{l}\text { 1. стадия инициации, 2. стадия планирования, 3. стадия исполнения, 4. стадия окончания. } \\
\text { 1. stage of initiation, 2. stage of planning, 3. stage of execution, 4. stage of graduation. }\end{array}$ \\
\hline $\begin{array}{l}\text { Ф. Бэгьюли } \\
\text { P. Bagueler }\end{array}$ & $\begin{array}{l}\text { 1. этап технико-экономического обоснования; } \\
\text { 2. этап планирования и разработки; } \\
\text { 3. этап производственный; } \\
\text { 4. этап заключительный } \\
\text { 1. stage of feasibility study; } \\
\text { 2. the planning and development phase; } \\
\text { 3. the stage of production; } \\
\text { 4. the final stage }\end{array}$ \\
\hline $\begin{array}{l}\text { M.B. Романова } \\
\text { M.V. Romanova }\end{array}$ & $\begin{array}{l}\text { 1. инициация (начальная фаза). 2. Фаза разработки (промежуточная фаза). 3. Фаза ис- } \\
\text { полнения (промежуточная фаза). 4. Фаза контроля (промежуточная фаза). 5. Фаза за- } \\
\text { вершения (конечная фаза). } \\
\text { 1. Initiation (initial phase). } 2 \text {. Development phase (intermediate phase). 3. Phase of execution (inter- } \\
\text { mediate phase). 4. Control phase (intermediate phase). 5. The completion phase (final phase). }\end{array}$ \\
\hline
\end{tabular}


Официально принятые определения понятия инновация

Table 2 .

Formally accepted definitions of the concept of innovation

\begin{tabular}{|c|c|}
\hline Ист & on \\
\hline $\begin{array}{l}\text { Оксфордский толковый сло- } \\
\text { варь. } \\
\text { Oxford } \quad \text { Explanatory } \\
\text { Dictionary }\end{array}$ & $\begin{array}{l}\text { Любой новый подход к конструированию, производству или сбыту товара, в } \\
\text { результате чего новатор или его компания получают преимущество перед кон- } \\
\text { курентами } \\
\text { Any new approach to the design, production or sale of goods, as a result of which the } \\
\text { innovator or his company gain an advantage over competitors }\end{array}$ \\
\hline $\begin{array}{l}\text { Федеральный закон РФ } \\
\text { «О науке и государственной } \\
\text { научно-технической политике» } \\
\text { Federal Law of the Russian Fed- } \\
\text { eration "On Science and the State } \\
\text { Scientific and Technical Policy" }\end{array}$ & $\begin{array}{l}\text { введённый в употребление новый или значительно улучшенный продукт (то- } \\
\text { вар, услуга) или процесс, новый метод продаж или новый организационный ме- } \\
\text { тод в деловой практике, организации рабочих мест или во внешних связях }{ }^{1} \text {. } \\
\text { introduced new or significantly improved product (product, service) or process, a new } \\
\text { sales method or a new organizational method in business practice, workplace organ- } \\
\text { ization or in external relations }\end{array}$ \\
\hline $\begin{array}{l}\text { Современная энциклопедия } \\
\text { Modern Encyclopedia }\end{array}$ & $\begin{array}{l}\text { то же, что нововведение }{ }^{2} \text {. } \\
\text { same as novation }\end{array}$ \\
\hline $\begin{array}{l}\text { Финансовый словарь Финам } \\
\text { Financial Dictionary Finam }\end{array}$ & $\begin{array}{l}\text { буквально инвестиции в новации, вложение средств в разработку новой тех- } \\
\text { ники, технологии, научные исследования }{ }^{3} \text {. } \\
\text { literally investing in innovation, investing in the development of new technology, } \\
\text { technology, scientific research }\end{array}$ \\
\hline $\begin{array}{l}\text { Словарь иностранных слов } \\
\text { Dictionary of foreign words }\end{array}$ & $\begin{array}{l}\text { вложение средств в новую технологию, новые формы организации труда и управления, } \\
\text { охватывающие не только отдельное предприятие, но и их совокупность, отрасль } \\
\text { investing in new technology, new forms of organization of labor and management, } \\
\text { covering not only a single enterprise, but also their aggregate, industry }\end{array}$ \\
\hline $\begin{array}{l}\text { Стратегический и инноваци- } \\
\text { онный менеджмент. Тер- } \\
\text { мины и определения } \\
\text { Strategic and innovative man- } \\
\text { agement. Terms and Defini- } \\
\text { tions }\end{array}$ & $\begin{array}{l}\text { Конечный результат инновационной деятельности, получивший реализацию в } \\
\text { виде нового или усовершенствованного продукта, реализуемого на рынке, но- } \\
\text { вого или усовершенствованного технологического процесса, используемого в } \\
\text { практической деятельности }{ }^{4} \text {. } \\
\text { The final result of innovation activity, which has been realized as a new or improved } \\
\text { product sold on the market, a new or improved technological process used in practice }\end{array}$ \\
\hline $\begin{array}{l}\text { Большой толковый словарь } \\
\text { по культурологии } \\
\text { Great Dictionary of Cultural } \\
\text { Studies }\end{array}$ & $\begin{array}{l}\text { выработка, синтезирование новых идей, создание новых моделей действия, } \\
\text { ценностей, политических программ, имеющих часто индивидуальный и непо- } \\
\text { вторимый характер. Инновация культурная впервые появляющиеся в данном } \\
\text { обществе (культуре) объекты, институты, черты, нормы, ценности в результате } \\
\text { изобретения или заимствования из других культур [Кононенко Б.И., 2003]. } \\
\text { the development, synthesis of new ideas, the creation of new models of action, values, po- } \\
\text { litical programs that often have an individual and unrepeatable character. Cultural innova- } \\
\text { tion is the first appearing in this society (culture) objects, institutions, features, norms, values } \\
\text { as a result of inventiveness or borrowing from other cultures [Kononenko B.I., 2003]. }\end{array}$ \\
\hline
\end{tabular}

В 60-е годы XX века в следствие развития исследований инноваций, а также определения их роли и важности в ходе экономического развития возникла необходимость статистического учета подобных исследований и разработок. Для обеспечения этого учета в 1963 г. Было принято руководство по проведению таких статистических исследований - «Руководство Фраскатти» ${ }^{5}$. В дальнейшем оно послужило основой для создания международных стандартов статистики науки, техники и инноваций. В соответствии с этими стандартами, инновация это конечный результат инновационной деятельности, получивший воплощение в виде нового усовершенствованного продукта, внедренного на рынке, нового усовершенствованного технологического процесса, используемого в практической деятельности, либо в новом подходе к социальным услугам.

\footnotetext{
${ }^{1}$ Федеральный закон «О внесении изменений в Федеральный закон «О науке и государственной научно-технической политике»» $\mathrm{N} 254-\Phi 3$ от 21 июля 2011 года

${ }^{2}$ URL:http://dic.academic.ru/dic.nsf/enc1p/19758 дата обращения: 01.02.2016

${ }^{3} \mathrm{https} / / / \mathrm{www}$. finam.ru/dictionary дата обращения: 01.02.2016

${ }^{4}$ ГОСТ Р 54147-2010: Стратегический и инновационный менеджмент. Термины и определения

${ }^{5}$ Стандартотчетностипонаучнымисследованиямиразработкам (ProposedStandardPracticeforSurveysofResearchandExperimentalDevelopment theFrascatiManual). - ОЭСР, 2002. - $150 \mathrm{c}$.
} 


\section{Becmник BTYYHTI/Proceedings of VSVET, TI. 79, № 4, 2017}

Таким образом, в этом определении делается акцент на том, что инновации оказываются бессмысленными без их интенсивного распространения.

Ф. Удвадиа определяет инновацию как относящуюся к: а) принятию деятельности илиновых технологий, являющихся новыми для организации; б) изменениям в структуре организации или используемой в ней управленческой практике; в) адаптации к рыночным условиям результатов внутрикорпоративных исследований и процессов организационного развития. Р. Смитс рассматривает инновацию как успешную комбинацию оборудования, технологий и организационного ресурса в контексте определённой социальной либо экономической модели.

Большинство авторов, рассматривающих понятие инновации (таблица Таблица3), исходят

позиции Й. Шумпетера, являющегося общепризнанным авторитетом в экономической науке по данной проблеме. Опираясь на мнение Ж.-Б. Сея о том, производство чего-либо является комбинацией имеющихся вещей и сил, он определяет инновации как нечто новое или произведенное отличным от имеющихся способом, т. е. новые комбинации вещей и сил.

Другая трактовка термина «инновация» менее широка и учитывает только научно-техническую сторону создания новых технологии

или новой продукции. Например, П. Друкерв работе «Эффективное управление. Экономические задачи и оптимальные решения» приводит следующее определение инновации: инновация - это разработка и внедрение нового, ранее не существовавшего, с помощью которого старые, известные элементы придают новые очертания экономике данного бизнеса/

Одним из основных ученых по данной проблеме, на идеи которого опирается большинство психологических работ, является С. Московичи. Согласно С. Московичи, инновация является единицей социального влияния, источником которого обычно является меньшинство или индивид, старающийся либо ввести или создать новые представления, понятия, способы мышления или поведения, либо изменить принятые представления, мнения, традиционные позиции и прежние способы мышления или поведения.

Приведенные определения отражают только одну сторону инноваций - экономическую (как некий новый товар) или психологическую (как единицу социального влияния). Данные подходы интегрированы в экономико-психологическом подходе к изучению инноваций, предложенном А.Н. Неверовым [Губайдуллина, Неверов, 2015]. Инновация в его работах представляет собой новое экономическое благо.

Таблица 3 .

Определения понятия «инновация»

Definitions of the concept of "innovation"

Table 3.

\begin{tabular}{|c|c|c|}
\hline Автор & Определение & Примечание \\
\hline $\begin{array}{l}\text { P. Смитс } \\
\text { R. Smits }\end{array}$ & $\begin{array}{l}\text { Инновация - успешная комбинация оборудования, тех- } \\
\text { нологий и организационного ресурса в контексте опреде- } \\
\text { лённой социальной либо экономической модели } \\
\text { Innovation is a successful combination of equipment, tech- } \\
\text { nologies and an organization resource in the context of a spe- } \\
\text { cific social or economic model }\end{array}$ & $\begin{array}{l}\text { Как новая комбинация } \\
\text { As a new combination }\end{array}$ \\
\hline $\begin{array}{l}\text { П. Друкер } \\
\text { Р. Drucker }\end{array}$ & $\begin{array}{l}\text { Инновация - это разработка и внедрение нового, ранее не } \\
\text { существовавшего, с помощью которого старые, извест- } \\
\text { ные элементы придают новые очертания экономике дан- } \\
\text { ного бизнеса... } \\
\text { Innovation is the development and implementation of a new, pre- } \\
\text { viously not existing, with the help of which old, known elements } \\
\text { bring new outlines to the economy of this business ... }\end{array}$ & $\begin{array}{l}\text { Как итоговый результат творче- } \\
\text { ского процесса и внедрения нового } \\
\text { As the final result of the creative } \\
\text { process and the introduction of a } \\
\text { something new }\end{array}$ \\
\hline $\begin{array}{l}\text { A.Н. Неверов } \\
\text { A.N. Neverov }\end{array}$ & $\begin{array}{l}\text { Инновация - новое экономическое благо, т. е. новый про- } \\
\text { дукт, обладающий редкостью и полезностью } \\
\text { Innovation is a new economic good, that is, a new product } \\
\text { that has a rarity and utility }\end{array}$ & $\begin{array}{l}\text { Как новый продукт, удовлетворя- } \\
\text { ющий потребности и имеющийся } \\
\text { в ограниченном количестве } \\
\text { As a new product, satisfying the } \\
\text { needs and having a limited number }\end{array}$ \\
\hline $\begin{array}{l}\text { C. Московичи } \\
\text { S. Moskovici }\end{array}$ & $\begin{array}{l}\text { Инновация - единица социального изменения } \\
\text { Innovation is a unit of social change }\end{array}$ & $\begin{array}{l}\text { Как изменение в обществе } \\
\text { As a change in society }\end{array}$ \\
\hline $\begin{array}{l}\text { Й. Шумпетер } \\
\text { J. Schumpeter }\end{array}$ & $\begin{array}{l}\text { Инновация - новая комбинация вещей и сил } \\
\text { Innovation - a new combination of things and forces }\end{array}$ & $\begin{array}{l}\text { Как новый продукт } \\
\text { As a new product }\end{array}$ \\
\hline
\end{tabular}


Исходя из приведенных выше работ, как классических, так и более поздних, следует, что инновационная деятельность это в первую очередь процесс создания новой комбинации ресурсов (вещей и сил). Инноватор может быть изобретателем и подобрать необходимые ресурсы для дальнейшего превращения новшества в новое экономическое благо, а может найти человека (скомбинировать человеческие ресурсы), который сможет воплотить его идею в жизнь.

Инновационная деятельность безусловно носит творческий характер. Творчество - процесс деятельности, создающий качественно новые материальные и духовные ценности или итог создания объективно нового. Основной критерий, отличающий творчество от изготовления (производства), - уникальность его результата [Общая..., 1986]. Однако творчество не в чистом виде [Неверов, 2010]. В основе инновационной деятельности лежит особый вид творчества творчество экономическое [Неверов, 2010]. Есть несколько определений того, что же из себя представляет экономическое творчество. Согласно одному из них - это особая функция экономической деятельности, направленная на экономические нововведения (изготовление нового блага или обеспечение нового качества того или иного уже существующего блага, внедрение нового или усовершенствование старого метода производства, освоение нового рынка сбыта, получение нового источника сырья и полуфабрикатов, проведение эффективной реорганизации, напр., обеспечение монопольного положения или подрыв монопольного положения др. предприятия и т. д.). ${ }^{6}$ Данное определение полностью отражает, что результатом экономического творчества является инновация (новое благо). Согласно другому определению, результатом экономического творчества может выступить оптимизация экономического процесса организации: экономическое творчество направлено на поиск оптимального использования экономических рычагов и стимулов для обеспечения конкурентоспособности предприятий социальной сферы путем повышения качества предлагаемых продуктов и услуг и снижения цен на них.

Исходя из приведенных выше определений, экономическое творчество - это процесс поиска путей оптимизации существующей социально-экономической системы через создание новых продуктов.

Инновационная деятельность на наш взгляд может быть разделена на два основных этапа (рисунок 1). Первый этап начинается с возникновения идеи у основного участника процесса инноватора. На первом этапе происходит подбор и обоснование необходимых ресурсов для реализации этой идеи. Формализован результат этого этапа может быть в четкий план работы, содержащий описание необходимых ресурсов. Второй этап по сути является не инновационной деятельностью, а экономической. Любой человек, имеющий отношение к бизнесу иреализации проектов может согласно плану реализовывать создание нового блага. Однако преимущества проектного подхода состоит в гибкой методологии. Согласно данной методологии возможна коррекция плана на всех этапах реализации. Это обезопасит инноватора от того, чтобы его не исключили из процесса реализации проекта. На наш взгляд именно это и различает предпринимателя в том смысле слова, котором его понимал Й. Шумпетер и бизнесмена, занимающегося рутинной экономической деятельностью. Когда идея начинает реализовываться необходимы навыки экономической бизнесдеятельности по продвижению нового блага, такие же как и любого другого.

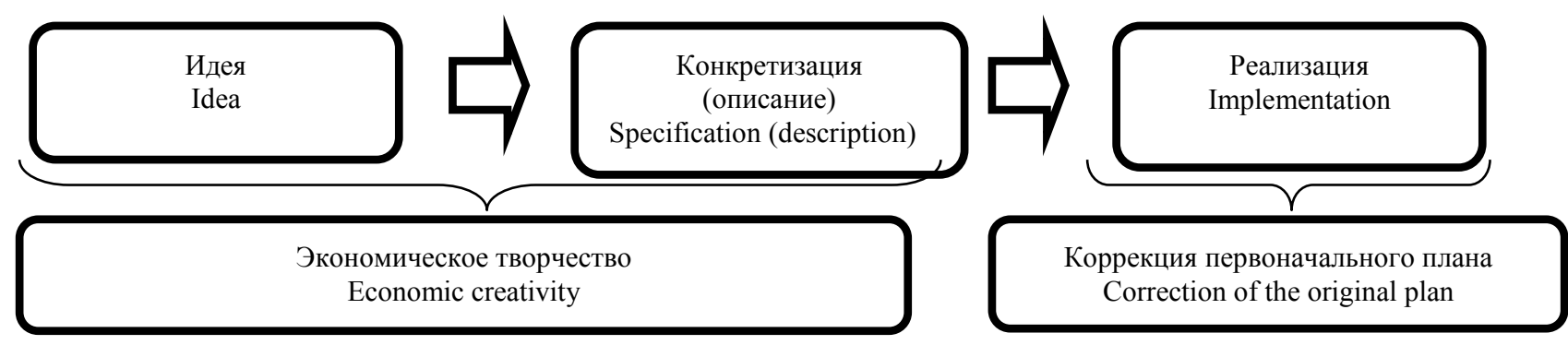

Рисунок 1. Этапы инновационной деятельности

Figure1. Stages of innovation

${ }^{6} \mathrm{URL}$ : http://www.potencial-school.ru/tvorchestvo-ekonomicheskoe.html дата обращения: 01.02.2016 


\section{Вестник BTYYTII/Proceedings of VSUET, TII. 79, № 4, 2017}

Описание процесса создания и вывода его на рынок хорошо укладывается в структуру стандартного бизнес-плана. Основным отличием выступает необходимость юридической защиты предмета интеллектуальной деятельности. В связи с этим, мы предполагаем, что для организации и реализации инновационного проекта необходимы следующие вспомогательные сектора. Для реализации инновационного проекта, на наш взгляд, необходимы следующие основные и вспомогательные элементы.

Ядром системы выступает сам автор идеи - «генератор» инновации. Автор проекта, выступающий его основным инициатором. Он может выступать в единственном числе, подбирать себе команду единомышленников, разделяющих его идею, или представлять собой коллектив из нескольких человек.

Сектор маркетинга. В отличие от типичных экономических задач в целях обеспечение инновационного проекта данный сектор должен обладать знаниями и навыками, необходимыми для привлечения внимания к новому продукту и определения и последующего занятия рыночной ниши.

Экономический сектор необходим для определения и необходимых затрат и возможных рисков и эффектов от реализации конкретного проекта.

Юридический сектор необходим для обеспечения защиты интеллектуальной собственности, следовательно должен специализироваться на особенностях патентного права и регистрации НИОКР.

Технический сектор необходим для осуществления организационно-технического сопровождения проекта, снижая таким образом бюрократическую нагрузку с автора проекта и его команды. Необходимы знания основ организации работы в сфере НИОКР.

Одним из важнейших секторов обеспечения организации инновационных проектов на наш взгляд выступает психологический сектор. Исходя из психологического анализа инновационной деятельности, проведенного нами в рамках работы 2011-2016 гг., было выявлено, что основными мотивами успешных инноваторов являются принесение пользы себе и обществу, а также реализация проекта, интерес в самом его воплощении, а не только в получении прибыли от ее реализации [Минасян, 2016]. На наш взгляд модель проектной деятельности в сфере инноваций должна отличаться от других видов деятельности включением обязательного психологического блока в организацию деятельности.

Психологический сектор оказывает поддержку на стадии разработки проектов при помощи специализированных тренинговых методик. Выступает фасилитаторами на обсуждениях, помогает проводить мозговые штурмы. Работают с поддержанием мотивации и интереса в процессе дальнейшей реализации процесса, либо дают рекомендации по коррекции и смене командного состава.

На первом этапе психологическое сопровождение может включать следующие виды работ:

- Мозговой штурм. Оперативный метод решения проблемы на основе стимулирования творческой активности, при котором участникам обсуждения предлагают высказывать как можно большее количество вариантов решения, в том числе самых фантастичных [Шмаков, Колесник, Костарева, 2015]. Данный метод должен быть особо эффективен на этапе оформления идеи и подбора возможных вариантов реализации.

- Методики решения изобретательских задач (на основе теории и алгоритма решения изобретательских задач (ТРИЗ, АРИЗ)) с целью активизации творческих ресурсов и преодоления возникающих в процессе реализации проекта противоречий.

- Оперативные совещания с применением методики фасилитации со стороны профессионального психолога. На оперативных совещаниях возможна коррекция первоначального плана в управляемой фасилитатором среде.

Приведенные выше методики способствуют организации творческой среды, необходимой для реализации проектной деятельности в сфере инноваций.

На втором этапе реализации проектной деятельности на наш взгляд необходимы следующие мероприятия:

- Презентация промежуточных результатов. На наш взгляд одной из основных проблем организации инновационной деятельности является высокая степень бюрократизации и сложность контроля промежуточных итогов. В качестве одного из способов решения этой проблемы может стать смена формы предоставления отчета о деятельности. Изложение промежуточных результатов на бумаге не отражает в полной мере картину продвижения проекта и чаще всего представляет собой формальный набор индикаторов. Заполнение набора отчетных документов занимает время основных участников проекта, при этом эффективность данного вида контроля низка. Мы предлагаем смену формальной бюрократической отчетности публичной презентацией промежуточных результатов с целью выявления слабых мест и пополнения идей взглядами со стороны привлеченных участников мероприятия.

- Оперативные совещания целью определения необходимости коррекции плана, возможно также с участием фасилитатора. 
- Поддержка интереса исполнителей к процессу при помощи различных мотивационных тренинговых методик (мотивационные беседы, банки идей, позитивное подкрепление).

Одним из основных секторов сопровождения таким образом наряду с экономическим и юридическим является психологическое сопровождение проекта.

Таким образом, модель проектной структуры (рисунок 2) должна включать два основных элемента: жесткое ядро и вспомогательный пояс.

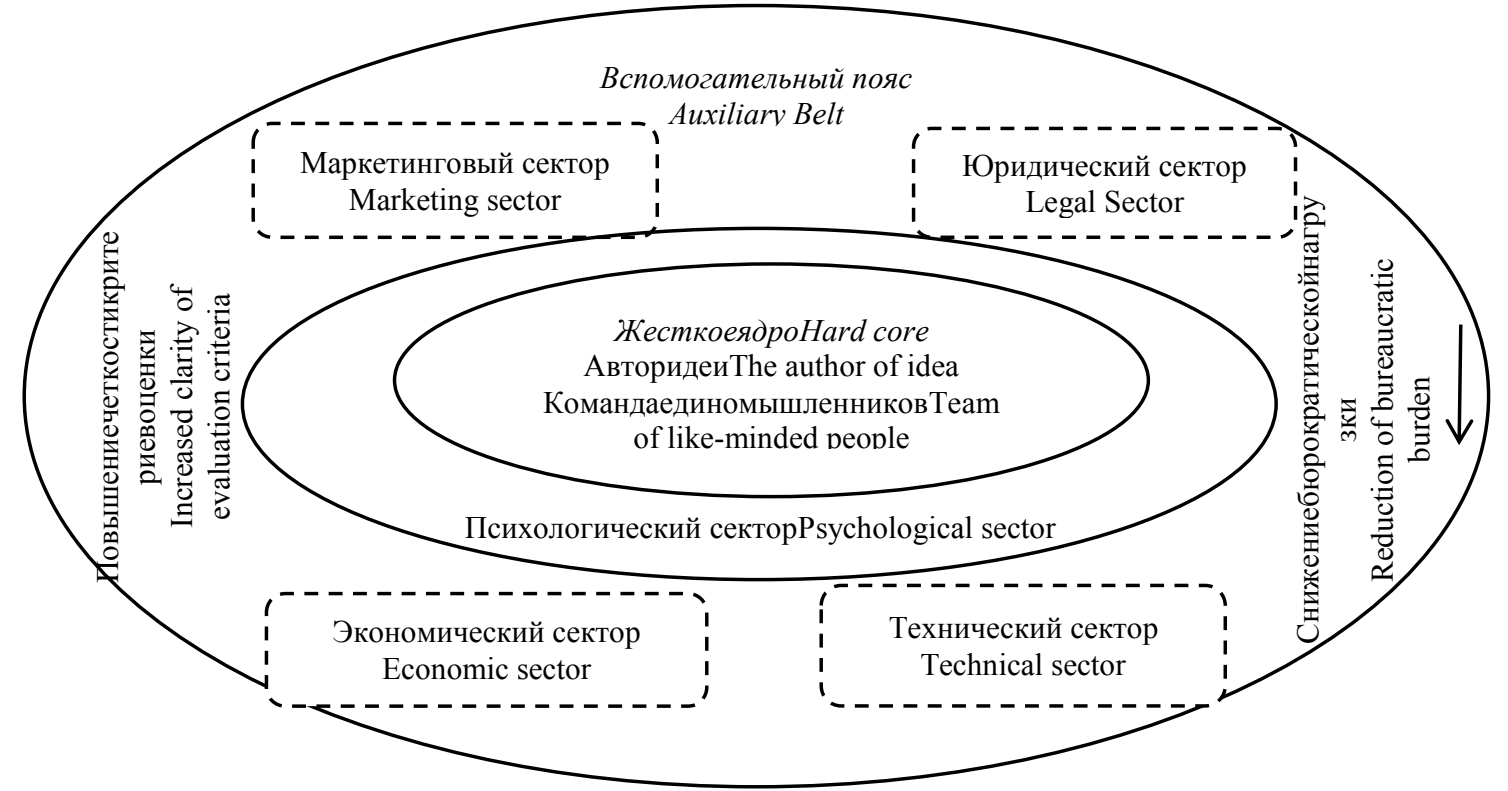

Рисунок 2. Модель организации проектной работы в сфере инноваций

Figure 2. Model of organization of project work in the field of innovations

В первую очередь предлагаемая модель приведет к снижению бюрократической нагрузки в первую очередь за счет подключения технического персонала, отвечающего непосредственно за подготовку необходимой технической документации. Во-вторых, снижение бюрократической нагрузки возможно за счет определения максимально четких временных рамок и критериев оценки результата.

\section{Заключение}

Каждый из секторов вспомогательного пояса несет свою функциональную нагрузку. Возможен вариант реализации, когда в существующих отделах на предприятии будет определена единица, занимающаяся поддержкой

\section{ЛИТЕРАТУРА}

1 Байбаева М. Х., Маркаева Д., Исмаилова Х. Понятие об инновациях в образовании, их классификация // Молодой ученый. 2016. №4. С. 744-746. URL https://moluch.ru/archive/108/25653.

2 Губайдуллина Г.Г. К вопросу о ведущем мотиве инновационной деятельности // Вестник Нижегородского университета им. Н.И. Лобачевского. Серия: Социальные науки. 2014. № 3 (35). С. 57-64.

3 Губайдуллина Г.Г., Неверов А.Н. Уровень организованности психологической структуры личности инноватора // Экономическая психология: современные проблемы и перспективы развития Пятнадцатая международная научно-практическая юбилейная конференция: материалы конференции. 2015. С. 51-54. инновационных проектов, осуществляющая вспомогательные функции. В другом варианте данная единица будет оказывать консультационную поддержку. Также вспомогательный пояс может как входить в команду, если инноватор самостоятельно привлечет соответствующих специалистов, так и основываться на консультационной поддержки соответствующих организаций или консультационных центры при проектных офисах. Наш взгляд предлагаемая модель организации проектной работы в сфере инноваций позволит реализовывать инновационные проекты с максимальной эффективностью и учетом не только экономических особенностей новых проектов, но и психологии инноватора «генератора» новых идей.

4 Минасян Г.Г. Эмпирическая модель психологической структуры инновационной деятельности бизнесмена // Экономическая психология: прошлое, настоящее, будущее. 2016. № 3-1. С. 157-165.

5 Оксфордский толковый словарь. URL: http://www.oed.com.

6 Шмаков А.Г., Колесник Е.А., Костарева Л.В. Метод мозгового штурма // Теория и опыт применения интерактивных методов обучения в вузе сборник научных трудов. Челябинский государственный университет. Челябинск, 2015. С. 185-198.

7 Javed B., Naqvi S., Khan A., Arjoon S. Impact of inclusive leadership on innovative work behavior: The role of psychological safety // Journal of Management \& Organization. 2017. URL: https://doi.org/10.1017/jmo.2017.3 
8 De Jong, Jeroen P.J. Entrepreneurial Behavior by Employees in Organizations. 2016. URL: SSRN: https://ssrn.com/abstract=2721615or http://dx.d oi.org/10.2139/ssrn.2721615

9 Śledzik K. Schumpeter's View on Innovation and Entrepreneurship // Management Trends in Theory and Practice, (ed.) Stefan Hittmar, Faculty of Management Science and Informatics, University of Zilina \& Institute of Management by University of Zilina, 2013.

10 Tur-Sinai O.M. Technological Progress and Well-Being Loy. U. Chi L.J. 2016. № 145.

11 Yesil, S., Sozbilir, F. An empirical investigation into the impact of personality on individual innovation behaviour in the workplace. Procedia // Social \& Behavioral Sciences. 2013. № 81. C. 540-551.

\section{REFERENCES}

1 Bajbaeva M. H., Markaeva D., Ismailova H. The concept of innovation in education, their classification. Molodoj uchenyj [Young scientist] 2016. no. 4. pp. 744-746. Available at: https://moluch.ru/archive/108/25653. (in Russian)

2 Gubajdullina G.G. To the question of the leading motive of innovation activity. Vestnik Nizhegorodskogo universiteta im. N.I. Lobachevskogo. Serija: Social'nye nauki. [Bulletin of the Nizhny Novgorod University named after. N.I. Lobachevsky. Series: Social Sciences] 2014. no. 3 (35). pp. 57-64. (in Russian)

3 Gubajdullina G.G., Neverov A.N. Level of organization of the psychological structure of the innovator's personality. Jekonomicheskaja psihologija: sovremennye problemy i perspektivy razvitija Pjatnadcataja mezhdunarodnaja nauchno-prakticheskaja jubilejnaja konferencija: materialy konferencii. [Economic Psychology: Contemporary Problems and Development Prospects Fifteenth International Scientific and Practical Jubilee Conference: conference materials]. 2015. pp. 51-54. (in Russian)

\section{СВЕДЕНИЯ ОБ АВТОРАХ}

Гульнара Г. Минасян младший научный сотрудник, Центр психолого-экономических исследований СНЦРАН, Поволжский институт управления имени П.А. Столыпина (филиал РАНХиГС), ул. Радищева, 41, Саратов, 410003, Россия, gubaidyllina@mail.ru

\section{КРИТЕРИЙ АВТОРСТВА}

Гульнара Г. Минасян Полностью подготовила рукопись и несет ответственность за плагиат

КОНФЛИКТ ИНТЕРЕСОВ

Автор заявляет об отсутствии конфликта интересов.

ПОСТУПИЛА 08.09.2017

ПРИНЯТА В ПЕЧАТЬ 03.11.2017
4 Minasjan G.G. Empirical model of psychological structure of innovative activity of a businessman. Jekonomicheskaja psihologija: proshloe, nastojashhee, budushhee. [Economic psychology: past, present, future] 2016. no. 3-1. pp. 157-165. (in Russian)

5 Oksfordskij tolkovyj slovar' [Oxford Explanatory Dictionary] Available at: http://www.oed.com.

6 Shmakov A.G., Kolesnik E.A., Kostareva L.V. The method of brainstorming. Teorija i opyt primenenija interaktivnyh metodov obuchenija $\mathrm{v}$ vuze sbornik nauchnyh trudov. Cheljabinskij gosudarstvennyj universitet ; pod obshhej redakciej A. G. Shmakova. Cheljabinsk [Theory and experience of the application of interactive teaching methods in the university collection of scientific papers. Chelyabinsk State University] 2015. pp. 185-198. (in Russian)

7 Javed B., Naqvi S., Khan A., Arjoon S. Impact of inclusive leadership on innovative work behavior: The role of psychological safety. Journal of Management \& Organization, 2017 https://doi.org/10.1017/jmo.2017.3

8 De Jong, Jeroen P.J. Entrepreneurial Behavior by Employees in Organizations. 2016. Available at SSRN: https://ssrn.com/abstract=2721615 or http://dx.doi.org/10.2139/ssrn.2721615

9 Śledzik K. Schumpeter's View on Innovation and Entrepreneurship. Management Trends in Theory and Practice, (ed.) Stefan Hittmar, Faculty of Management Science and Informatics, University of Zilina \& Institute of Management by University of Zilina, 2013.

10 Tur-Sinai O.M. Technological Progress and Well-Being Loy. U. Chi L.J. 2016. no. 145.

11 Yesil, S., Sozbilir, F. An empirical investigation into the impact of personality on individual innovation behaviour in the workplace. Procedia. Social \& Behavioral Sciences. 2013. no. 81. pp. 540-551.

\section{INFORMATION ABOUT AUTHORS}

Gulnara G. Minasyan junior researcher, Center of psychoeconomic researches of SSC RAS, Stolypin Volga Region Institute of Adminstration (branch of RANEPA), Radishcheva str., 41, 410003, Russia, gubaidyllina@mail.ru

\section{CONTRIBUTION}

Gulnara G. Minasyan Completely prepared the manuscript and is responsible for plagiarism

\section{CONFLICT OF INTEREST}

The author declare no conflict of interest.

RECEIVED 9.8.2017

ACCEPTED 11.3.2017 